\title{
Histopathological Spectrum of Ovarian Lesion in a Tertiary Care Hospital over a Period of Five years
}

\author{
Dr. Nehal Ahmad ${ }^{1}$, Dr. Mohammad Jaseem Hassan ${ }^{2 *}$, Dr. Sabina Khan ${ }^{3}$, Dr. Zeeba S. Jairajpuri ${ }^{4}$, Dr. Sujata Jetley ${ }^{5}$ \\ ${ }^{1}$ Assistant Professor, ${ }^{2-4}$ Associate Professor, ${ }^{5}$ Professor, Department of Pathology, Hamdard Institute of Medical Sciences and Research (HIMSR), \\ Jamia Hamdard, New Delhi, India
}

\begin{abstract}
DOI: $10.36348 /$ sjpm.2019.v04i11.017 $\quad$ | Received: 20.11.2019| Accepted: 27.11.2019| Published: 30.11 .2019
*Corresponding author: Dr. Mohammad Jaseem Hassan
\end{abstract}

\section{Abstract}

Introduction: Ovarian lesions are commonly encountered lesions of diverse morphological spectrum that may develop from neonatal period to post-menopause. They are amongst the most frequent cause of hospitalization and surgery in gynaecological practice. Distinguishing non-neoplastic lesion from a neoplastic lesion on the basis of clinical, radiological or gross characteristics alone is a challenge, thus histopathological examination is must as it is also important in guiding therapy. Objectives: This study was undertaken to study the various histopathological patterns of ovarian lesions, their classification and relative distribution of these lesions. Material and Methods: This is a retrospective study of ovarian lesion specimen that was received in the Histopathology section of our department over a period of 5 years from January 2013 to December 2017. Results: A total of 190 cases of ovarian lesions were included in this study with age range from 14 years to 75 years. 106 were non-neoplastic and 84 were neoplastic in nature. Functional cyst including Corpus luteal cyst was the commonest non-neoplastic lesion (26 cases) followed by 21 cases each of endometriotic cyst and simple cyst. Out of 84 neoplastic lesions, 74 were benign, 3 were Borderline and 7 were malignant in nature. Serous cystadenoma was the commonest benign lesion and Serous carcinoma was the most common malignant tumor in our study. Conclusions: Ovarian lesions comprises of wide spectrum of lesions and their presenting clinical, radiological and gross features are very similar. Hence Histopathology forms the mainstay of definitive diagnosis and categorization of these lesions.

Keywords: Neoplastic Lesion, Non-neoplastic lesion, Ovary, Ovarian cyst, serous cystadenoma.

Copyright @ 2019: This is an open-access article distributed under the terms of the Creative Commons Attribution license which permits unrestricted use, distribution, and reproduction in any medium for non-commercial use (NonCommercial, or CC-BY-NC) provided the original author and sources are credited.

\section{INTRODUCTION}

Ovaries are a pair of primary reproductive organ that lies in the true pelvis on either side of uterus. Their main functions is to produce eggs or ova and production of reproductive hormones estrogen and progesterone. Although they are small organ but they are common site of lesions of diverse morphological spectrum that may develop from neonatal period to post-menopause. These lesions are generally categorized into non-neoplastic and neoplastic lesions that are further sub-categorized into a variety of lesions depending on multiple factors. Non-neoplastic lesion consists predominantly of functional cyst (Corpus luteal cyst, Follicular cyst) and other non-neoplastic benign pathology including endometriotic cyst, tubo-ovarian abscess, cyst of polycystic ovarian syndrome, inflammatory lesions, surface epithelial inclusion cyst etc. Functional cyst are frequently seen in young female in their $2^{\text {nd }}$ decades due to failure of ovulation. However, fewer cases could also be seen in perimenopausal and postmenopausal women [1]. In most cases they resolve spontaneously. Surgical treatment is required for large, persistent, or painful ovarian cysts [2]. Neoplastic lesions are categorized into Benign, Borderline and Malignant. The histogenesis of ovarian tumours revolves around the four main components namely Surface epithelium, Germ cell, Sex cord and Ovarian stroma, specialized and nonspecific [3]. There also are histologic differences in the type of tumors found in the younger and older populations, germ cell neoplasms predominate in prepubertal children and young adults, whereas lesions of epithelial origin are rare in this age group but are predominantly seen in elderly and postmenopausal women [4]. Among all the ovarian neoplasm about $80 \%$ are benign having cystic, solid or mixed characteristics [5]. The remaining $20 \%$ of these tumours are malignant in nature leading to fatal prognosis [6]. Distinguishing non-neoplastic lesion from a neoplastic lesion is a challenge clinically and is important in guiding therapy. Even non neoplastic cystic lesions are also frequently responsible for a 
pelvic mass and associated with abnormal hormonal manifestations often mimicking a neoplasm thus causing diagnostic confusion. They are diagnosed on histopathology [7]. Ovarian cancer accounts for $2.5 \%$ of all malignancies among females but $5 \%$ of female cancer deaths because of low survival rates, largely driven by late stage diagnosis [8]. Ovarian cancer is the fourth most common cancer in India. Ovarian cancer usually has a relatively poor prognosis since it lacks early detection or screening tests, implying that most cases are not diagnosed until they have reached advanced stages [9]. Improving prevention and early detection is a research priority because disease diagnosed at a local stage has a 5-year relative survival rate of $93 \%$ [8].

Knowing the above facts about the broad spectrum of presentation of ovarian lesion and importance of histological diagnosis for proper management, this study was conducted to exactly categorize the different type of ovarian lesion, their age relation, their brief clinical presentation and associated pathological findings.

\section{MATERIALS AND METHODS}

This retrospective study was conducted in the department of Pathology at our institute over a period of 5 years from January 2013 to December 2017. Clinical data was retrieved from histopathology requisition form/hospital records of patients presenting with ovarian lesion. All the specimens(biopsies/surgical specimens) that were received in our histopathology section were fixed in $10 \%$ formalin, embedded in paraffin, sectioned at $3-5 \mu$ and stained with Hematoxylin and Eosin. Special stains like Periodic acid Schiff(PAS) was done as and when required. All the specimens of ovarian lesions including hysterectomy specimen at histopathology section of pathology were included in the study. Previously treated cases of ovarian lesion with recurrence were excluded from the study. Descriptive statistical measures were utilized to present the data. A total of 190 cases of ovarian lesions fulfilling these criteria were finally included in this study. Histologically ovarian lesions were classified into non-neoplastic masses and neoplastic masses. Non-neoplastic masses were further subdivided into different types of cysts, other lesions, and neoplastic masses were divided as benign, borderline and malignant lesions.

\section{RESULTS}

A total of 190 cases presented as ovarian lesions was included in this study. Minimum age of the patients presenting with the ovarian lesion in our study was 14 years while maximum age was 75 years. Mean age of presentation was 29.33 years. Ovarian lesions were most common in the age group of 21-30 years, comprising of $62(32.5 \%)$ cases. [Table 1] Overall a total of 106 cases were seen in the reproductive age group range of 21-40 years. A total of $170(89.5 \%)$ cases were unilateral while $20(10.5 \%)$ cases were bilateral. [Table 2] Among unilateral lesions, 108(56.8\%) cases were seen on the right ovary while $62(32.6 \%)$ cases were seen on the left ovary. 106 cases were nonneoplastic while 84 cases were neoplastic. Among neoplastic cases, 74 cases were benign, 3 cases were categorized as borderline and 7 cases were malignant. Maximum number of non-neoplastic lesions were seen in 21-30 year age group(36 cases) followed by 31-40 year age group(11 cases). Maximum number of neoplastic benign lesion were also seen in 21-30 years age $\operatorname{group}(26$ cases $)$ followed by 31-40year age group(20 cases). Among malignant lesion 3 cases were seen in 41-50 year age group followed by 2 cases in 5160year age group however one case was seen in $11-20$ year age group. Most of the ovarian lesion presented with pain abdomen(89/190) followed by swelling abdomen (46/190) either alone or in combination with pain abdomen. Other presenting symptoms were abnormal uterine bleeding (27/190) in the form of menorrhagia or metrorrhagia, primary or secondary infertility, amenorrhea or dysmenorrhea in occasional cases. [Table-3] 28 cases were asymptomatic. Associated findings in specimens of Hysterectomy with salpingo-oophorectomy were also found. Most common was leiomyoma either alone or in combination with adenomyosis. Other associated findings were chronic cervicitis, carcinoma endometrium, carcinoma cervix; hydrosalpinx etc. [Table- 4] Systemic symptoms in some of the lesions were ascites, hypothyroidism, diabetes mellitus, hypertension etc. Corpus luteal cyst was the most common non-neoplastic lesion with 26 cases $(24.5 \%)$ followed by 21 cases each of endometriotic cyst(19.8\%) [Fig-1D] and simple cyst $(19.8 \%)$. [Table- 5] Other non-neoplastic lesion were Cystic follicle (14 cases), Follicular cyst and Parovarian cyst (6 cases each), hemorrhagic cyst, ectopic gestation, Torsion ovary, Inclusion cyst and oophoritis. Among the neoplastic lesions, surface epithelial tumors was the most common(61 cases) followed by Germ cell tumor(18 cases) and metastatic tumors( 3 cases) [Table6]. Among the Benign lesion, Serous cystadenoma [Fig1A] was the most commonly encountered lesion with $40(47.6 \%)$ cases, followed by Dermoid cyst(18 cases), and Mucinous cystadenoma(11 cases) [Fig-1B]. one case each of Serous Cystadenofibroma [Fig-1C], Seromucinous cystadenoma, Brenner's tumour and Thecoma is also seen. Among Borderline lesions, two cases of Borderline Serous cystadenoma and one case of Atypical proliferative endometrioid tumour [Fig-2A] were recorded. Among the malignancies, Serous carcinoma was the most common comprising of three cases, [Fig-2B] while three cases of Metastatic carcinoma from different sites to bilateral ovary recorded. [Fig-2C\&2D]. One case of Endometroid carcinoma was also seen [Table 7]. 
Table-1: Age distribution of all cases of ovarian lesions

\begin{tabular}{|c|c|c|c|c|c|c|}
\hline $\begin{array}{l}\text { Age } \\
\text { group }\end{array}$ & $\begin{array}{l}\text { No \& \% of non- } \\
\text { neoplastic lesion }\end{array}$ & $\begin{array}{c}\text { No \& \% of } \\
\text { neoplastic lesion }\end{array}$ & $\begin{array}{l}\text { No \& \% of Benign } \\
\text { neoplastic lesion }\end{array}$ & $\begin{array}{c}\text { No \& \% of Borderline } \\
\text { neoplastic lesion }\end{array}$ & $\begin{array}{c}\text { No \& \% of } \\
\text { Malignant lesion }\end{array}$ & $\begin{array}{c}\text { Total } \\
\text { Number }\end{array}$ \\
\hline $0-10$ & $00(0.0)$ & $00(0.0)$ & $00(0.0)$ & $00(0.0)$ & $00(0.0)$ & $00(0.0)$ \\
\hline $11-20$ & $04(3.77)$ & $06(7.14)$ & $05(6.7)$ & $00(0.0)$ & $01(14.28)$ & $10(5.5)$ \\
\hline $21-30$ & $36(33.9)$ & $26(30.9)$ & $26(35.1)$ & $00(0.0)$ & $00(0.0)$ & $62(32.5)$ \\
\hline $31-40$ & $23(21.6)$ & $21(25)$ & $20(27.02)$ & $00(0.0)$ & $01(14.28)$ & $44(23)$ \\
\hline $41-50$ & $26(24.5)$ & $20(23.8)$ & $16(21.6)$ & $01(33.3)$ & $03(42.8)$ & $46(24)$ \\
\hline $51-60$ & $13(12.2)$ & $08(9.5)$ & $05(6.75)$ & $01(33.3)$ & $02(28.6)$ & $21(11.5)$ \\
\hline $61-70$ & $02(1.88)$ & $02(2.38)$ & $02(2.70)$ & $00(0.0)$ & $00(0.0)$ & $4(2.0)$ \\
\hline $71-80$ & $02(1.88)$ & $01(1.19)$ & $00(0.0)$ & $01(33.3)$ & $00(0.0)$ & $3(1.5)$ \\
\hline Total & $106(100)$ & $84(100)$ & $74(100)$ & $03(100)$ & $07(100)$ & $190(100)$ \\
\hline
\end{tabular}

Table 2: Laterality of ovarian Lesion

\begin{tabular}{|c|c|c|c|}
\hline Laterality & Side & Number \& \% age & Total No. \& \% age \\
\hline Unilateral & Right & $108(56.8)$ & $170(89.5)$ \\
\hline & Left & $62(32.6)$ & \\
\hline Bilateral & & $20(10.5)$ & $20(10.5)$ \\
\hline & & $190(100)$ & $190(100)$ \\
\hline
\end{tabular}

Table- 3: Clinical presentation of all the cases of Ovarian Lesions

\begin{tabular}{|l|c|}
\hline \multicolumn{1}{|c|}{ Clinical presentation } & Number of cases \\
\hline Pain Abdomen & 71 \\
\hline Swelling abdomen & 31 \\
\hline Pain abdomen and swelling abdomen & 15 \\
\hline Abnormal uterine bleeding (AUB) & 27 \\
\hline Pain abdomen and AUB & 3 \\
\hline Infertility & 13 \\
\hline Amenorrhoea & 02 \\
\hline Asymptomatic & 28 \\
\hline Total & 190 \\
\hline
\end{tabular}

Table-4: Associated conditions associated with ovarian lesion

\begin{tabular}{|c|c|}
\hline Associated Conditions & No. of Cases \\
\hline Adenomyosis & 05 \\
\hline Leiomyoma & 29 \\
\hline Adenomyosis and Leiomyoma & 12 \\
\hline Chronic cervicitis & 23 \\
\hline Prolapse & 01 \\
\hline Hydrosalpinx & 03 \\
\hline Carcinoma Endometrium & 04 \\
\hline Hypothyroidism & 04 \\
\hline Endometrial intraepithelial Neoplasia & 01 \\
\hline Carcinoma Cervix & 01 \\
\hline Diabetes Mellitus & 02 \\
\hline Hypertension & 02 \\
\hline Total & $\mathbf{8 7}$ \\
\hline
\end{tabular}

Table-5: Non-neoplastic lesions of ovary with laterality and number

\begin{tabular}{|c|c|c|c|c|}
\hline Types of cyst & Right & Left & Bilateral & Total \\
\hline Cystic follicle(CF) & 3 & 5 & 6 & $14(13.2)$ \\
\hline Follicular cyst(FC) & 1 & 3 & 2 & $6(5.60)$ \\
\hline Corpus Luteal Cyst(CLC) & 12 & 12 & 2 & $26(24.5)$ \\
\hline Hemorrhagic cyst(HC) & 3 & 1 & 0 & $4(3.77)$ \\
\hline Endometriotic cyst(EMC) & 11 & 6 & 4 & $21(19.8)$ \\
\hline Ectopic Gestation(EG) & 1 & 1 & 0 & $2(1.88)$ \\
\hline Inclusion Cyst(IC) & 2 & 0 & 0 & $2(1.88)$ \\
\hline Parovarian Cyst(PC) & 4 & 2 & 0 & $6(5.66)$ \\
\hline Simple Cyst(SC) & 12 & 9 & 0 & $21(19.8)$ \\
\hline Ovarian Abscess(OA) & 0 & 1 & 0 & $1(0.09)$ \\
\hline Chronic nonspecific oophoritis(CO) & 0 & 1 & 0 & $1(0.09)$ \\
\hline Xanthogranulomatous oophoritis(XO) & 1 & 0 & 0 & $1(0.09)$ \\
\hline Torsion ovary & 0 & 1 & 0 & $1(0.09)$ \\
\hline Total number of cases & 50 & 42 & 14 & $106(100)$ \\
\hline
\end{tabular}


Table-6: Categorization of Neoplastic Ovarian Lesion

\begin{tabular}{|c|c|}
\hline Type of ovarian tumour & Number \& Percentage (\%) \\
\hline Surface epithelial tumour & $61(72.6)$ \\
\hline Germ cell tumour & $18(21.4)$ \\
\hline Sex cord stromal tumour & $01(1.19)$ \\
\hline Metastatic tumour & $03(3.57)$ \\
\hline Others & $01(1.19)$ \\
\hline Total & $\mathbf{8 4}(\mathbf{1 0 0})$ \\
\hline
\end{tabular}

Table-7: Neoplastic lesions with laterality and number

\begin{tabular}{|c|c|c|c|c|c|}
\hline Category of Neoplastic lesion & Type of Neoplastic Lesion & Right & Left & Bilateral & Total Number \\
\hline \multirow{4}{*}{ Benign } & Serous cystadenoma & 31 & 09 & 0 & $40(47.6)$ \\
\cline { 2 - 5 } & Dermoid cyst & 11 & 05 & 02 & $18(21.4)$ \\
\cline { 2 - 5 } & Mucinous Cystadenoma & 07 & 04 & 0 & $11(13.0)$ \\
\cline { 2 - 5 } & Serous Cystadenofibroma & 01 & 0 & 0 & $01(1.10)$ \\
\cline { 2 - 5 } & Seromucinous Cystadenoma & 01 & 0 & 0 & $01(1.10)$ \\
\cline { 2 - 5 } & Brenner Tumour & 0 & 01 & 0 & $01(1.10)$ \\
\cline { 2 - 6 } & Thecoma & 01 & 0 & 0 & $01(1.10)$ \\
\cline { 2 - 5 } & Benign Lipomatous lesion & 01 & 0 & 0 & $01(1.10)$ \\
\hline \multirow{4}{*}{ Borderline Tumour } & Borderline Serous cystadenoma & 02 & 0 & 0 & $02(2.38)$ \\
\cline { 2 - 6 } & Atypical proliferative endometrioid tumour & 0 & 01 & 0 & $01(1.10)$ \\
\hline \multirow{4}{*}{ Malignant } & & 02 & 0 & 01 & $03(3.57)$ \\
\cline { 2 - 6 } & Serous carcinoma & 01 & 0 & 0 & $01(1.10)$ \\
\cline { 2 - 6 } & Endometroid carcinoma & 0 & 0 & 03 & $03(3.57)$ \\
\hline
\end{tabular}

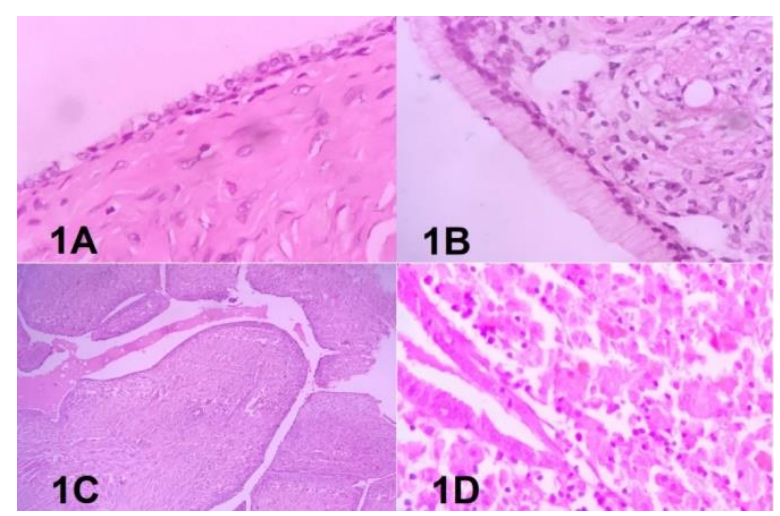

Fig-1: 1A- Serous Cystadenoma: Cyst lined by single layer of flattened to cuboidal epithelium. (H\&E x 400). 1B- Mucinous Cystadenoma: Cyst lined by single layé of columnar mucinous epithelium showing mucin filled cells with basally located nuclei. (H\&E x 400). 1C-Serous Cystadenofibroma: Broad papillae lined by single layer of epithelium. Highly cellular and fibrous stroma is seen beneath the epithelium. (H\&E $x$ 100). 1D- Endometriosis: Numerous hemosiderin laden macrophages surrounding endometrial glands. (H\&E x 400)

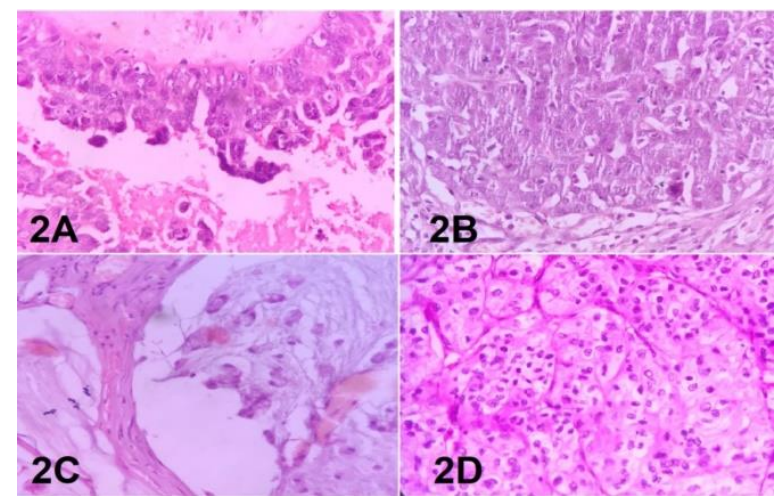

Fig-2: 2A- Atypical proliferative endometrioid tumour: Photomicrograph shows epithelial stratification, tufting and detachment of individual cells and cell clusters. (H\&E x 400). 2B- Serous carcinoma: Photomicrograph shows solid sheets of markedly atypical cells with occasional mitosis. (H\&E x 400). 2C- Metastatic Mucinous Carcinoma: Photomicrograph shows signet ring cells lying in pool of mucin. (H\&E x 400). 2DMetastatic clear cell carcinoma: Diffuse sheets and tubules of clear cells having clear to eosinophilic cytoplasm and cells are separated by vascular core. (H\&E x 400) 


\section{DISCUSSION}

Ovarian lesions form a complex group of lesions with a broad spectrum of clinical and histopathological features. A total number of 190 cases were included in our study. Age of the patients ranged from 14 years to 75 years. Mean age group recorded was 29.33 years. In a study by Farooq et al. mean age of females for all ovarian masses was $40.61 \pm 13.74$ years [10]. Overall most common age group affected were young reproductive female (21-30 years). Both non-neoplastic and neoplastic benign lesions were common to this age group. This is similar to other reports where most of the benign ovarian lesions occur in women of reproductive age groups [11, 12]. Neoplastic malignant lesions were most common in 4150 year age group but it has been seen in all age groups including reproductive, perimenopausal, and postmenopausal women. A study by Murthy NS et al. involving data across various cities in India revealed that the incidence of ovarian cancer increases from 35 years of age reaching its peak between 55-64 years [13, 14]. Most of the studies from western world as well as from. India reported ovarian malignancy most commonly in the age group of 40 years and abobe [15, 16]. The rationale for these variations could be attributed to poverty, short life expectancy, and ignorance in most developing countries including India.

Our study revealed that 170 out of 190 ovarian specimens were unilateral $(89.5 \%)$ and only $20(10.5 \%)$ were bilateral, similar to study by Gurung et al. (88.15\% unilateral and $11.85 \%$ bilateral) [17] and Thakkar and Shah (88.4\% unilateral) [18]. Our findings vary slightly by the study done by Kanithkar et al. in which $78.18 \%$ tumours were unilateral and $21.82 \%$ tumours were bilateral [19].

In Benign and malignant ovarian neoplasm, pain in abdomen was the most common complaint, followed by lump abdomen. Kanthikar SN et al. and Pilli et al. also observed similar clinical presentation in non-neoplastic lesions. [19, 20].

Grossly, it was found in our study that nonneoplastic as well as benign tumours were mostly cystic as compared to malignant, which were solid in consistency followed by partly cystic and partly solid which is in accordance with other studies [20].

In present study, out of 190 cases, 106 lesions were non-neoplastic (55.8\%) while 84 lesions (44.2\%) were neoplastic lesion. This is similar to study by Martinez-Onsurbe $\mathrm{P}$ et al. who reported 55 cases $(41.67 \%)$ of non-neoplastic lesions, out of total 132 ovarian lesions and Kreuzer GF et al. reported 82 $(40.39 \%)$ non-neoplastic lesions, out of 203 ovarian lesions[21,22]. Gurung et al. found $43.7 \%$ nonneoplastic lesions and $56.3 \%$ neoplastic lesion in their study [17].
Among non-neoplastic lesions, Functional cysts were the most common lesions. Corpus luteal cysts including hemorrhagic corpus luteum cysts was the most commonly encountered ovarian lesions. This is followed by Simple cysts and Endometriotic cysts. This finding is similar to studies done by Choi and Kim where corpus luteum cyst was the most commonly encountered ovarian lesions [22]. Farooq et al. Abdullah et al. Also observed that corpus luteum cyst was the most frequently encountered functional cyst of the ovary $[10,23]$. However, these similar reports are in contrast to reports from Italy by Guerriero et al. where endometrioma was the most common ovarian mass followed by the functional cysts [24] Yasmin et al. [25] from Pakistan, Maliheh et al. from Iran[26], and Thakar et al. [18] from India in their studies reported follicular cysts as the most common non-neoplastic lesion. The reason for this variation cannot be fully ascertain, but may be attributable to environmental, hormonal, and genetic influences. Other commonly diagnosed cysts in our study include simple/serous cysts. Studies have also supported the fact that these cysts are also commonly reported by other researchers globally [27, 28]. In our study, inflammatory masses are only $3(2.8 \%)$ while another study showed $10.6 \%$ inflammatory masses [29].

In current study among 84 neoplastic lesions, $74(88 \%)$ cases were benign, $3(3.6 \%)$ cases were of borderline nature while $7(8.4 \%)$ cases were malignant. This is in synchrony with the study of Sheikh et al. $\mathrm{N}$ Gupta et al.[30,31] while contradictory to study by Ahmad $\mathrm{Z}$ et al. where malignant lesion was comparatively high(40.6\%)[32].

Using the WHO criteria to classify ovarian tumors, it is conventionally known that surface epithelial was the most common lesion seen globally. In our study, also surface epithelial tumors were the most common ovarian tumors $(73 \%)$. However, the germ cell tumor $(21.3 \%)$ was the second most encountered ovarian tumors in our locality [Table-6]. This report is in contradiction with reports from India by Sheikh et al. [30], Lagos by Onyiaorah et al. where germ cell tumor was the most common ovarian lesion followed by surface epithelial tumors [33]. Pilli et al. reported that ovarian epithelial surface tumors accounted for $70.9 \%$ of all ovarian tumors; this is followed by germ cell tumors constituting $21.2 \%$. Sex cord stromal tumors and metastatic tumors constituted 2.1 and $6.7 \%$, respectively [20]. Studies from the West also showed that surface epithelial tumours were the most common ovarian neoplasia [34]. Similar observations were made by Gupta et al.[31].

In surface epithelial tumour, Serous Cystadenoma was the most common benign neoplasm followed by Mucinous Cystadenoma. This finding coincided with previous studies by Gupta et al. [32] Similar results have been reported by Yasmin et al. and Narang et al.[25,35] Teratoma was the most common 
Germ cell tumour found in our study contributing 18 cases $(21.68 \%)$ of all ovarian tumours which is comparable to the results observed in studies carried out by Yasmin et al. and Zaman et al. Which were showing $18 \%$ and $19.35 \%$ respectively $[25,36]$. A single case of Brenner's tumour was also reported in our study.

Borderline ovarian tumours are of low malignant potential having favorable prognosis and relatively early age at onset [37]. They comprise 4\%$14 \%$ of all epithelial ovarian neoplasms [38]. In our study, we diagnosed 3 cases $(3.6 \%)$ of borderline ovarian tumour including 2 cases of Borderline serous papillary neoplasm and one case of Atypical proliferative endometrioid tumour

In the present study, serous cystadenocarcinoma (3.61\%) was the commonest malignant epithelial neoplasm followed by Endometrioid adenocarcinomas (1.2\%). This was close to study by Zaman et al. who reported serous cystadenocarcinoma (4.5\%) and Endometrioid adenocarcinomas (3.87\%) [36]. Sharma I et al. reported serous cystadenocarcinoma $(4.8 \%)$ and Endometrioid adenocarcinoma (3.2\%) [39], but our study contradicts with the study of Krishna $\mathrm{M}$ et al. who reported higher percentage $(10.4 \%)$ of Serous Cystadenocarcinoma [40].

Metastases to the ovaries are relatively frequent with the most common being from the endometrium, breast, colon, stomach, and cervix [41]. Metastatic tumour (3 cases) constituted $3.61 \%$ of all the neoplastic ovarian lesion in our study and all of them were bilateral. Zaman et al. in his study reported single case of Metastatic tumour from breast [36]. Among sexcord stromal tumour, a single case of Thecoma was diagnosed in our study.

\section{CONCLUSION}

Ovary, despite being a small pair of organ in female genital system has complex architecture with different cell types. Hence it encompasses broad group of lesion from non-neoplastic to neoplastic benign, borderline and malignant lesion. In our study we have compared these lesions with multiple parameters like age, clinical presentation, and location of lump, associated lesions, and different histological subtypes. All these clinical and histomorphological parameters and advanced newer diagnostic modalities can help to arrive at early definitive diagnosis and to plan the line of treatment and also have prognostic significance. Both non-neoplastic as well as neoplastic lesions of ovary often present with similar clinical, radiological and surgical features. So histopathological study is essential to diagnose ovarian tumours and predict their prognosis. In cases of benign functional cysts spontaneous resolution may take place, so symptomatic treatment and observation may help to minimize surgery in these patients. Since most of the malignant cases are detected at a later stage, their early diagnosis can help in patient long survival and prognosis.

\section{REFERENCES}

1. Abduljabbar, H. S., Bukhari, Y. A., Al Hachim, E. G., Ashour, G. S., Amer, A. A., Shaikhoon, M. M., \& Khojah, M. I. (2015). Review of 244 cases of ovarian cysts. Saudi medical journal, 36(7), 834.

2. Holt, V. L., Cushing-Haugen, K. L., \& Daling, J. R. (2005). Risk of functional ovarian cyst: effects of smoking and marijuana use according to body mass index. American journal of epidemiology, 161(6), 520-525.

3. Rosai, J. (2011). Rosai and Ackerman's surgical pathology e-book. Elsevier Health Sciences.

4. Lalrinpuii, E., Bhageerathy, P. S., Sebastian, A., Jeyaseelan, L., Thomas, A., Chandy, R., \& Peedicayil, A. (2017). Ovarian cancer in young women. Indian journal of surgical oncology, 8(4), 540-547.

5. Tortolero-Luna, G., Mitchell, M. F., \& RhodesMorris, H. E. (1994). Epidemiology and screening of ovarian cancer. Obstetrics and gynecology clinics of North America, 21(1), 1-23.

6. Rashid, S., Sarwar, G., \& Ali, A. (1998). A clinicopathological study of ovarian cancer. Mother Child, 36, 117-25.

7. Clement, P. B. (2005). Selected miscellaneous ovarian lesions: small cell carcinomas, mesothelial lesions, mesenchymal and mixed neoplasms, and nonneoplastic lesions. Modern pathology, 18(S2), S113.

8. Howlader, N. A. M. N., Noone, A. M., Krapcho, M., Garshell, J., Miller, D., Altekruse, S. F., ... \& Mariotto, A. (2014). SEER cancer statistics review, 1975-2011. Bethesda, MD: National Cancer Institute, 19.

9. Saranath, D., \& Khanna, A. (2014). Current status of cancer burden: global and Indian scenario. Biomed Res $J, 1(1), 1-5$.

10. Farooq, F., Noman, D., Humayun, N., Naveed, N., \& Haider, A. (2015). Demographic differentials and histopathological patterns of ovarian masses. Biomedica, 31(2).

11. Mondal, S. K., Banyopadhyay, R., Nag, D. R., Roychowdhury, S., Mondal, P. K., \& Sinha, S. K. (2011). Histologic pattern, bilaterality and clinical evaluation of 957 ovarian neoplasms: A 10-year study in a tertiary hospital of eastern India. Journal of Cancer research and Therapeutics, 7(4), 433.

12. Forae, G. D., \& Aligbe, J. U. (2014). A histopathological overview of ovarian lesions in Benin City, Nigeria: How common are the functional cysts?. International Journal of Medicine and Public Health, 4(3).

13. Quirk, J. T., \& Natarajan, N. (2005). Ovarian cancer incidence in the United States, 1992 1999. Gynecologic oncology, 97(2), 519-523.

14. Murthy, N. S., Shalini, S., Suman, G., Pruthvish, S., $\&$ Mathew, A. (2009). Changing trends in incidence of ovarian cancer-the Indian scenario. Asian Pac $J$ cancer prev, 10(6), 1025-30.

15. Jha, R., \& Karki, S. (2008). Histological pattern of ovarian tumors and their age distribution. Nepal Med Coll J, 10(2), 81-85. 
16. Arab, M., Khayamzadeh, M., Hashemi, M., Hosseini, M., Tabatabaeefar, M., Anbiaee, R., ... \& Akbari, M. E. (2010). Crude and age-specific incidence rate patterns for histopathologic subtypes of ovarian cancer in Iran. Archives of Iranian medicine, 13(3), 203.

17. Gurung, P., Hirachand, S., \& Pradhanang, S. (2013). Histopathological study of ovarian cystic lesions in tertiary care hospital of Kathmandu, Nepal. Journal of Institute of Medicine, 35(3), 44-7.

18. Thakkar, N. N., \& Shah, S. N. (2015). Histopathological Study of Ovarian Lesion. International journal of Science and Research (IJSR), 4(10), 1745-9.

19. Kanthikar, S. N., Dravid, N. V., Deore, P. N., Nikumbh, D. B., \& Suryawanshi, K. H. (2014). Clinico-histopathological analysis of neoplastic and non-neoplastic lesions of the ovary: a 3-year prospective study in Dhule, North Maharashtra, India. Journal of clinical and diagnostic research: JCDR, 8(8), FC04.

20. Pilli, G. S., Suneeta, K. P., Dhaded, A. V., \& Yenni, V. V. (2002). Ovarian tumours: a study of 282 cases. Journal of the Indian Medical Association, 100(7), 420-423.

21. Martínez-Onsurbe, P., Villaespesa, A. R., Anquela, J. M. S., \& Ruiz, P. L. V. (2001). Aspiration cytology of 147 adnexal cysts with histologic correlation. Acta cytologica, 45(6), 941-947.

22. Choi, H. J., Kim, S. H., Kim, S. H., Kim, H. C., Park, C. M., Lee, H. J., ... \& Jeong, J. Y. (2003). Ruptured corpus luteal cyst: CT findings. Korean journal of radiology, 4(1), 42-45.

23. Abdullah, L. S., \& Bondagii, N. S. (2012). Histopathological pattern of ovarian neoplasms and their age distribution in the western region of Saudi Arabia. Saudi Med J, 33(1), 61-65.

24. Guerriero, S., Alcazar, J. L., Pascual, M. A., Ajossa, S., Gerada, M., Bargellini, R., ... \& Melis, G. B. (2009). Diagnosis of the most frequent benign ovarian cysts: is ultrasonography accurate and reproducible?. Journal of women's health, 18(4), 519527.

25. Yasmin, S., Yasmin, A., \& Asif, M. (2008). Clinicohistological pattern of ovarian tumours in Peshawar region. J Ayub Med Coll Abbottabad, 20(4), 11-3.

26. Arab, M., Hashemi, M., Masoumi, N., Yaseri, M., Golfam, F., \& Ebrahimi, M. (2010). Surgical Histopathology of Benign Ovarian. Iranian Journal of Pathology, 5(3), 132-136.

27. MacKenna, A., Fabres, C., Alam, V., \& Morales, V. (2000). Clinical management of functional ovarian cysts: a prospective and randomized study. Human reproduction, 15(12), 2567-2569.

28. Gabbur, N., Sherer, D. M., Hellmann, M., Abdelmalek, E., Phillip, P., \& Abulafia, O. (2006).
Do serum beta-human chorionic gonadotropin levels on day 4 following methotrexate treatment of patients with ectopic pregnancy predict successful single-dose therapy?. American journal of perinatology, 23(03), 193-196.

29. Borgfeldt, C., \& Andolf, E. (2004). Cancer risk after hospital discharge diagnosis of benign ovarian cysts and endometriosis. Acta obstetricia et gynecologica Scandinavica, 83(4), 395-400.

30. Sheikh, S., Bashir, H., Farooq, S., Beigh, A., Manzoor, F., \& Reshi, R. (2017). Histopathological spectrum of ovarian tumours from a referral hospital in Kashmir valley, Jammu and Kashmir, India. Int J Res Med Sci, 5(5), 2110-14.

31. Gupta, N., Bisht, D., Agarwal, A. K., \& Sharma, V. K. (2007). Retrospective and prospective study of ovarian tumours and tumour-like lesions. Indian journal of pathology \& microbiology, 50(3), 525-527.

32. Ahmad, Z., Kayani, N., Hasan, S. H., Muzaffar, S., \& Gill, M. S. (2000). Histological pattern of ovarian neoplasma. Journal of Pakistan Medical Association, 50(12), 416.

33. Onyiaorah, I. V., Anunobi, C. C., Banjo, A. A., Fatima, A. A., \& Nwankwo, K. C. (2011). Histopathological patterns of ovarian tumours seen in Lagos University Teaching Hospital: a ten year retrospective study. Nigerian quarterly journal of hospital medicine, 21(2), 114-118.

34. Parkin, D. M., Bray, F., Ferlay, J., \& Pisani, P. (2001). Estimating the world cancer burden: Globocan 2000. International journal of cancer, 94(2), 153-156.

35. Narang, S., Singh, A., Nema, S., \& Karode, R. (2017). Spectrum of ovarian tumours-a five year study. Journal of Pathology of Nepal,7(2), 11801183.

36. Zaman, S., Majid, S., Hussain, M., Chughtai, O., Mahboob, J., \& Chughtai, S. (2010). A retrospective study of ovarian tumours and tumour-like lesions. Journal of Ayub Medical College Abbottabad, 22(1), 104-108.

37. Levi, F., La Vecchia, C., Randimbison, L., \& Te, V. C. (1999). Borderline ovarian tumours in Vaud, Switzerland: incidence, survival and second neoplasms. British journal of cancer, 79(1), 4.

38. Burkholz, K. J., Wood, B. P., \& Zuppan, C. (2005). Borderline papillary serous tumor of the right ovary. Radiographics, 25(6), 1689-1692.

39. Sharma, I., Sarma, U., \& Dutta, U. C. (2014) Pathology of ovarian tumour-A hospital based study. Valley Int J, 1(6), 284-286.

40. Krishna, M., \& Maurya, G. (2015). Pattern of ovarian tumors and their age distribution in Kangra Valley, Himachal Pradesh. Journal of Evolution of Medical and Dental Sciences, 4(61), 10602-10609.

41. Lee-Jones, L. Ovarian tumours: an overview. Atlas Genet Cytogenet Oncol Haematol 2003. 